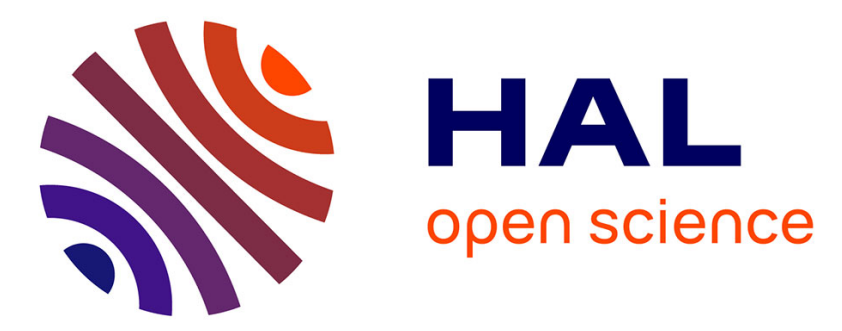

\title{
A Monte Carlo study of photoelectron extraction efficiency from CsI photocathodes into $\mathrm{XeCH} 4$ and $\mathrm{NeCH} 4$ mixtures
}

\author{
J Escada, T H V T Dias, P.J.B.M. Rachinhas, F P Santos, J a M Lopes, L C \\ C Coelho, C a N Conde, a D Stauffer
}

\section{To cite this version:}

J Escada, T H V T Dias, P.J.B.M. Rachinhas, F P Santos, J a M Lopes, et al.. A Monte Carlo study of photoelectron extraction efficiency from CsI photocathodes into $\mathrm{XeCH} 4$ and $\mathrm{NeCH} 4$ mixtures. Journal of Physics D: Applied Physics, 2010, 43 (6), pp.65502. 10.1088/0022-3727/43/6/065502 . hal-00569761

\section{HAL Id: hal-00569761 https://hal.science/hal-00569761}

Submitted on 25 Feb 2011

HAL is a multi-disciplinary open access archive for the deposit and dissemination of scientific research documents, whether they are published or not. The documents may come from teaching and research institutions in France or abroad, or from public or private research centers.
L'archive ouverte pluridisciplinaire HAL, est destinée au dépôt et à la diffusion de documents scientifiques de niveau recherche, publiés ou non, émanant des établissements d'enseignement et de recherche français ou étrangers, des laboratoires publics ou privés. 


\title{
A Monte Carlo study of photoelectron extraction efficiency from CsI photocathodes into $\mathrm{Xe}^{-\mathrm{CH}_{4}}$ and Ne- $\mathrm{CH}_{4}$ mixtures
}

\author{
J Escada ${ }^{1,3}$, T H V T Dias ${ }^{1}$, P J B M Rachinhas ${ }^{1,4}$, F P Santos ${ }^{1}$, J A M \\ Lopes $^{1,5}$, L C C Coelho ${ }^{1}$, C A N Conde ${ }^{1}$ and A D Stauffer ${ }^{2}$ \\ ${ }^{1}$ Departamento de Física, Universidade de Coimbra, 3004-516 Coimbra, Portugal \\ ${ }^{2}$ Physics and Astronomy Department, York University, Toronto, M3J 1P3 Canada
}

\begin{abstract}
The extraction efficiency $f$ for the photoelectrons emitted from a CsI photocathode into gaseous $\mathrm{Xe}-\mathrm{CH}_{4}$ and $\mathrm{Ne}-\mathrm{CH}_{4}$ mixtures is investigated by Monte Carlo simulation. The results are compared with earlier calculations in $\mathrm{Ar}_{-} \mathrm{CH}_{4}$ mixtures and in the pure gases $\mathrm{Xe}, \mathrm{Ar}, \mathrm{Ne}$ and $\mathrm{CH}_{4}$. The calculations examine the dependence of $f$ on the density-reduced electric field $E / N$ in the $0.1-40 \mathrm{Td}$ range, on the incident photon energy $E_{\mathrm{ph}}$ in the 6.8-9.8 eV (183-127 nm) VUV range and on the mixture composition. Results calculated for irradiation of the photocathode with a $\mathrm{Hg}(\mathrm{Ar}) \mathrm{lamp}$ are compared with experimental measurements for this lamp. To test the electron scattering cross-sections used in the simulations, electron drift parameters in Xe, $\mathrm{Ne}$ and their mixtures with $\mathrm{CH}_{4}$ are also presented and compared with available experimental data.

PACS 85.60.Gz, 51.10.+y, 29.40.Cs
\end{abstract}

\section{Introduction}

Cesium iodide photocathodes have been extensively used as UV converters in many applications, due to their high quantum efficiency, allied to good stability, resistance to ageing and easy production. In particular, they are frequently used in gas photosensor devices such as gas photomultipliers (GPMTs), gas electronmultipliers (GEMS), and other micro pattern gas devices, to detect the primary or/and secondary scintillation produced in radiation detectors [16]. However, the transmission of the photoelectrons may be significantly reduced due to backscattering of the photoelectrons in the gas, thus reducing the effective quantum efficiency of the photocathode, an effect which is especially important when the rate of elastic scattering is high, as in the noble gases. In the field of gaseous radiation detectors, and the emission of photoelectrons from CsI in particular, the effect has been investigated experimentally and by

\footnotetext{
${ }^{3}$ Corresponding author jescada@gian.fis.uc.pt

${ }_{5}^{4}$ Also at: Serviço de Radioterapia, Hospital da Universidade de Coimbra, 3000-075 Coimbra, Portugal.

${ }^{5}$ Also at: Instituto Superior de Engenharia de Coimbra, 3030-199 Coimbra, Portugal.
} 
Monte Carlo simulation, see [7-15] and references therein, where the dependence on gas and mixture composition, reduced applied electric field $E / N(E$ is the field strength and $N$ the number density) and incident photon energy $E_{\mathrm{ph}}$ was analyzed. In the broader field of swarm physics [16], which is fundamental to gas discharge and plasma physics, electron back-diffusion has been investigated for more than half a century, together with reflection effects and induced secondary emission [17-26]. In [24-26] Monte Carlo simulation was used to examine electron back-diffusion to an emitting frontier (cathode) in argon and nitrogen, showing in particular, as we also verified in [14], that transmission is very sensitive to the electron initial energy $\varepsilon_{0}$ and energy distribution profile, increasing in general with decreasing $\varepsilon_{0}$, with full transmission for $\varepsilon_{0}$ $=0$.

In previous work $[13,14]$ we have used Monte Carlo simulation to investigate the extraction efficiency $f$ of photoelectrons emitted from a CsI photocathode into $\mathrm{Xe}, \mathrm{Ar}, \mathrm{Ne}$ and their mixtures, and in $\mathrm{CH}_{4}$ and $\mathrm{Ar}-\mathrm{CH}_{4}$ mixtures, where $f$ is the fraction of the number of photoelectrons transmitted in the gas compared to vacuum. Due essentially to the electron energy cooling effect related to vibrational excitation of the $\mathrm{CH}_{4}$ molecules, which has a threshold at low electron impact energy, the addition of $\mathrm{CH}_{4}$ to noble gases efficiently increases electron transmission and drift velocity. We note that $f$ has been also referred to as transmission efficiency, collection efficiency or escape factor in the literature, but in the present work we adopt the more common designation extraction efficiency.

In the present work we extend the investigation to $\mathrm{Xe}_{-} \mathrm{CH}_{4}$ and $\mathrm{Ne}-\mathrm{CH}_{4}$ mixtures, and compare the results for $f$ with those previously obtained in $\mathrm{Ar}-\mathrm{CH}_{4}$ mixtures and in pure $\mathrm{Ne}, \mathrm{Ar}$, $\mathrm{Xe}$ and $\mathrm{CH}_{4}$. The Monte Carlo results are presented in Section 3.2 for reduced electric fields in the range $E / N=0.1$ to $40 \mathrm{Td}\left(1 \mathrm{Td}\right.$ (Townsend) $\left.=10^{-17} \mathrm{~V} \mathrm{~cm}^{2}\right)$ when the CsI photocathode is irradiated by monochromatic VUV photons with $E_{\mathrm{ph}}$ in the 6.7 to $9.8 \mathrm{eV}(185-127 \mathrm{~nm})$ range. The $6.7 \mathrm{eV}$ photons belong to the VUV peak of the spectral distribution of a $\mathrm{Hg}(\mathrm{Ar}) \mathrm{lamp}$, allowing us to compare with the available experimental data for $f$ obtained with this lamp. In addition, electron drift parameters in the pure gases $\mathrm{Xe}$ and $\mathrm{Ne}$ and their mixtures with $\mathrm{CH}_{4}$ were calculated and are compared with experimental data from the literature in Section 3.1.

\section{Monte Carlo simulation}

Detailed descriptions of the simulation model used in the calculations can be found in [13-15], but a summary will be given here.

The photoelectrons are emitted from the CsI photocathode surface $(z=0)$ into the gas at 1 atmosphere with initial energies $\varepsilon_{0}$ chosen either from the distributions measured in [27] when a reflective CsI photocathode was irradiated by monochromatic photons with sixteen $E_{\mathrm{ph}}$ values from 6.8 to $9.8 \mathrm{eV}$ ), or else from the specific $\varepsilon_{0}$ distribution measured in [28] when CsI was irradiated with $E_{\mathrm{ph}}=6.7 \mathrm{eV}$ photons from the $\mathrm{Hg}(\mathrm{Ar})$ lamp. The mean values of these $\varepsilon_{0}$ distributions range from 0.2 to $2 \mathrm{eV}$. The photoelectron emission angle into the gas is sampled in $[0, \pi / 2]$ from a distribution modulated by the so called escape cone in the solid for the given $\varepsilon_{0}$, as required by momentum conservation when electrons cross the barrier from CsI to gas or vacuum $[13,29]$. The simulation follows the drift of the individual photoelectrons in the gas under the influence of an applied uniform electric field perpendicular to the surface of the photocathode along successive free paths taking into account elastic and inelastic collisions with the gas atoms and molecules. The null-collision method [30-32] is used to reproduce the electron free paths between collisions. As in [14], all collisions with $\mathrm{CH}_{4}$ are assumed to be isotropic, but anisotropy of elastic scattering is accounted for by using the elastic momentum transfer cross-section [33]. To be consistent, a similar formalism is adopted for the elastic collisions with Xe or Ne. The electron history ends either when it hits the photocathode, and it is counted as recaptured, or when return to the photocathode becomes energetically forbidden 
(essentially when all the energy $\varepsilon_{0}$ has been lost in collisions), and it is counted as transmitted. The extraction efficiency $f$ which is the probability that a photoelectron will reach the anode is obtained as $f=m / m_{0}$, where $m$ is the number of electrons transmitted when at least $m_{0}=10^{6}$ photoelectrons are injected into the gas giving a statistical uncertainty below $1 \%$. Note that $f=1$ in vacuum for any $\varepsilon_{0}$, while in the gas $f=1$ for the limit $\varepsilon_{0}=0$. Reflection of backscattered electrons by the photocathode surface may occur [23-26], but reflection coefficients from CsI are not known and the calculations do not account for the effect.

The histories of recaptured photoelectrons often end shortly after emission into the gas, well before electrons reach equilibrium with the field (for instance, in $90 \mathrm{Xe}-10 \mathrm{CH}_{4}$ at $E / N=1 \mathrm{Td}$ and $E_{\mathrm{ph}}=8 \mathrm{eV}$, our simulations indicate that recapture occurs after $\sim 20$ collisions and $\sim 40 \mathrm{ps}$ on average). For the calculations of the electron drift parameters, though, a sample of $5 \times 10^{4}$ electrons with initial energies $\varepsilon_{0}=0$ is followed in the gas allowing a long enough drift time to guarantee that the parameters reach equilibrium values $[15]$ ( $\sim 5$ times the relaxation time, which is $\sim 4 \mathrm{~ns}$ in the case of $90 \mathrm{Xe}-10 \mathrm{CH}_{4}$ at $E / N=1 \mathrm{Td}$ ).

The cross-sections used in the simulation for the scattering of the electrons by $\mathrm{Xe}, \mathrm{Ar}$ and $\mathrm{Ne}$ atoms and by $\mathrm{CH}_{4}$ molecules are represented in figure 1.

In Xe, the elastic momentum transfer cross-section is based on [34-36] below $\sim 2 \mathrm{eV}$ and [37, 38 ] above $\sim 2 \mathrm{eV}$, the integral and partial cross-sections for excitation are obtained from [38] and [39], respectively, and the total ionization cross-section is from [40].

In $\mathrm{Ne}$, we take the cross-section for elastic momentum transfer from [41] below $20 \mathrm{eV}$ and [37] above $20 \mathrm{eV}$, and the inelastic scattering cross-sections are based on [42, 43] for integral excitation, on [39] for partial excitation and on [40,44] for ionization.

In $\mathrm{Ar}$ and $\mathrm{CH}_{4}$, the scattering cross-sections have been described in [14]; in $\mathrm{CH}_{4}$ they are mostly based on the compilation found in [45].

The present study is focused on the extraction at low $E_{\mathrm{ph}}$ and $\varepsilon_{0}$ of photoelectrons from CsI into $\mathrm{Xe}-\mathrm{CH}_{4}$ and $\mathrm{Ne}-\mathrm{CH}_{4}$ gas mixtures when a low drift field (usually below multiplication threshold) is applied in the gas, but the calculations are extended somewhat, up to $40 \mathrm{Td}$ for the extraction efficiency $f$ and $100 \mathrm{Td}$ for the drift parameters, neglecting eventual space charge effects. 

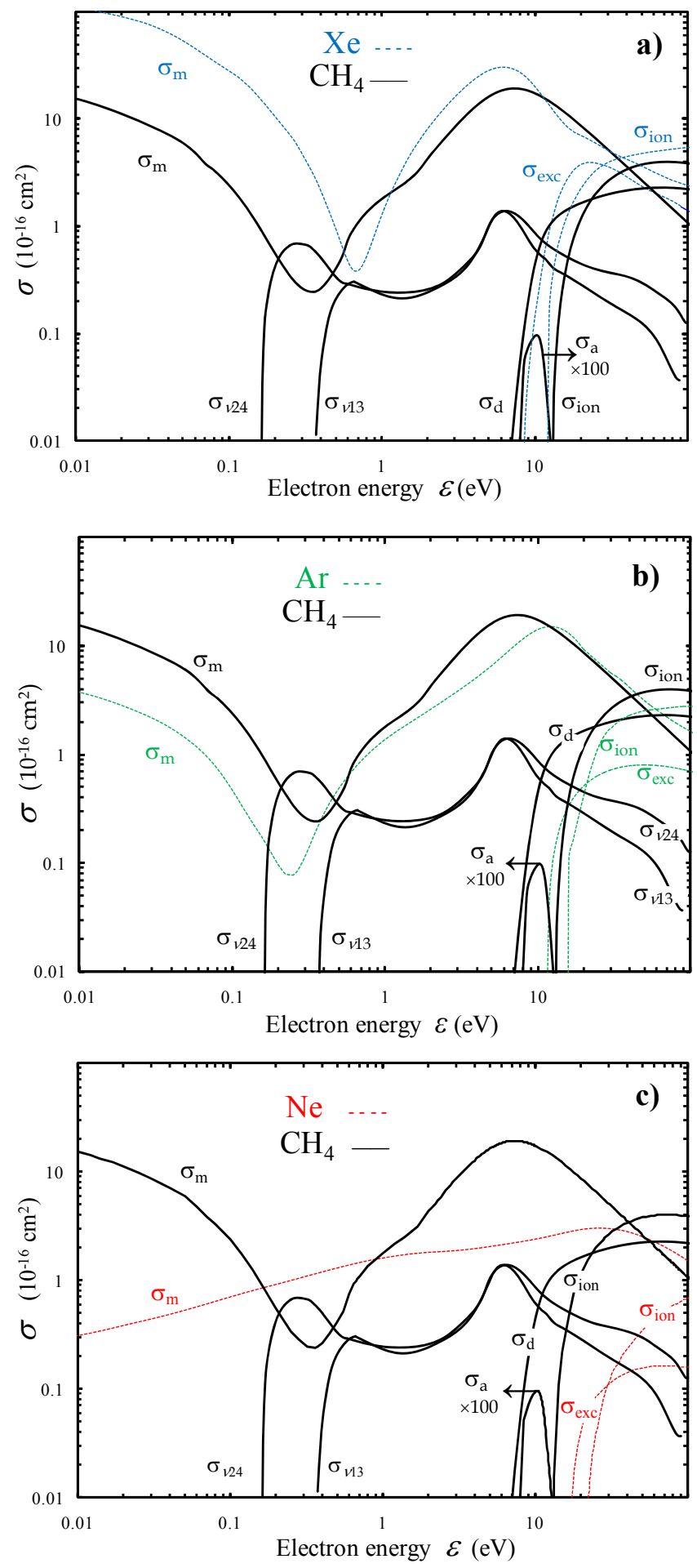

Figure 1. Electron scattering cross-sections a) in $\mathrm{Xe}$ and $\mathrm{CH}_{4}$, b) in $\mathrm{Ar}$ and $\mathrm{CH}_{4}$ and c) in $\mathrm{Ne}$ and $\mathrm{CH}_{4}: \sigma_{\mathrm{m}}$ - elastic momentum transfer; $\sigma_{v}$ - vibrational excitation, $\sigma_{\mathrm{a}}$ - electron attachment; $\sigma_{\mathrm{exc}}$ - electronic excitation; $\sigma_{\mathrm{d}}-$ neutral dissociation; $\sigma_{\mathrm{ion}}$ - ionization. 

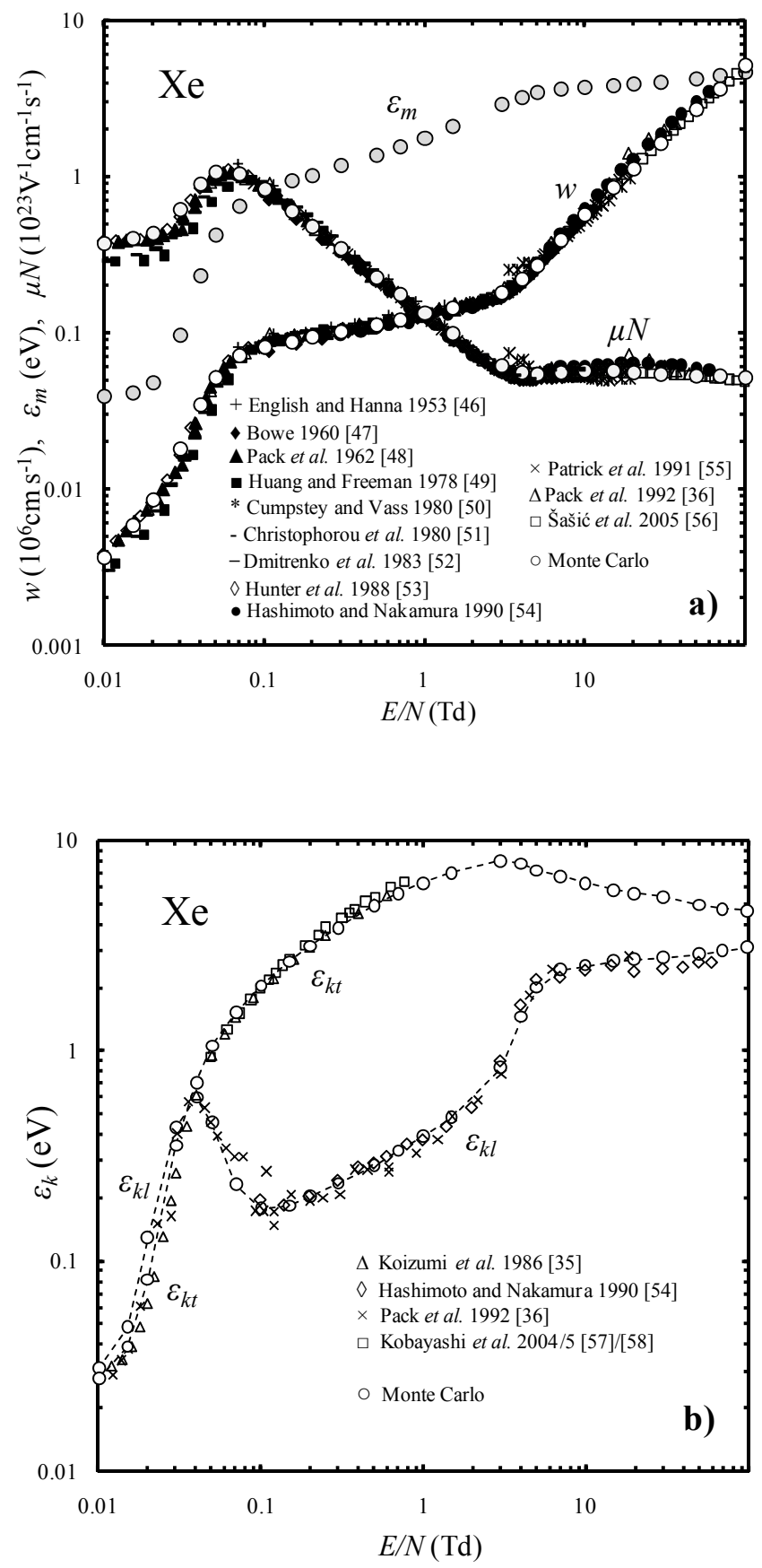

Figure 2. Monte Carlo results in Xe together with experimental data from the literature for a) electron mean energy $\varepsilon_{m}$, drift velocity $w$ and reduced mobility $\mu N$ and b) characteristic energies $\varepsilon_{k l}$ and $\varepsilon_{k t}$ as a function of the reduced electric field $E / N$. The dashed curves in b) are included to guide the eye. 

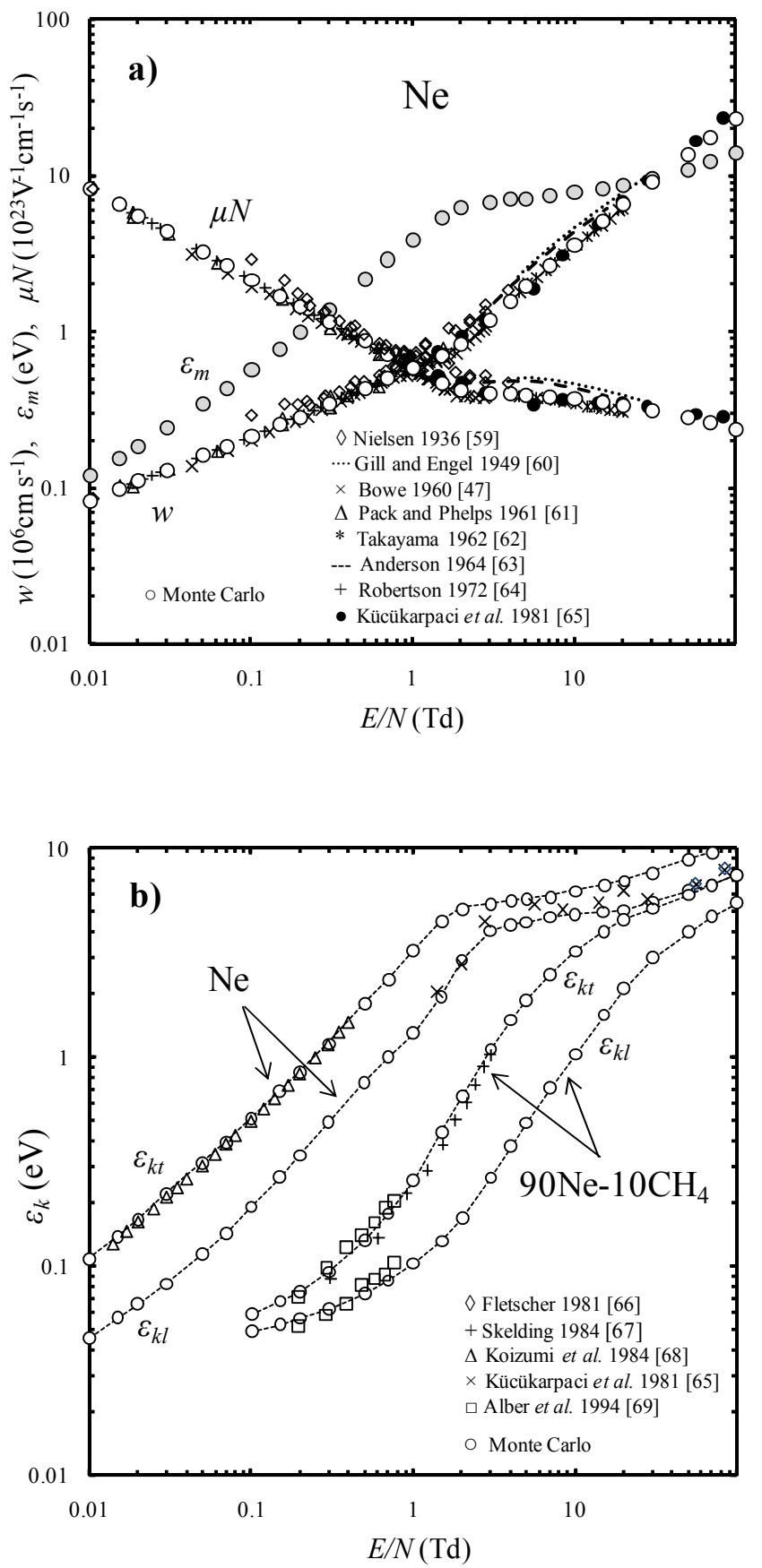

Figure 3. Monte Carlo results together with experimental data for a) electron mean energy $\varepsilon_{m}$, drift velocity $w$ and reduced mobility $\mu N$ in $\mathrm{Ne}$, and b) characteristic energies $\varepsilon_{k l}$ and $\varepsilon_{k t}$ in $\mathrm{Ne}$ and in the $90 \% \mathrm{Ne}-10 \% \mathrm{CH}_{4}$ mixture, as a function of the reduced electric field $E / N$. The dashed curves in $b$ ) are included to guide the eye. 

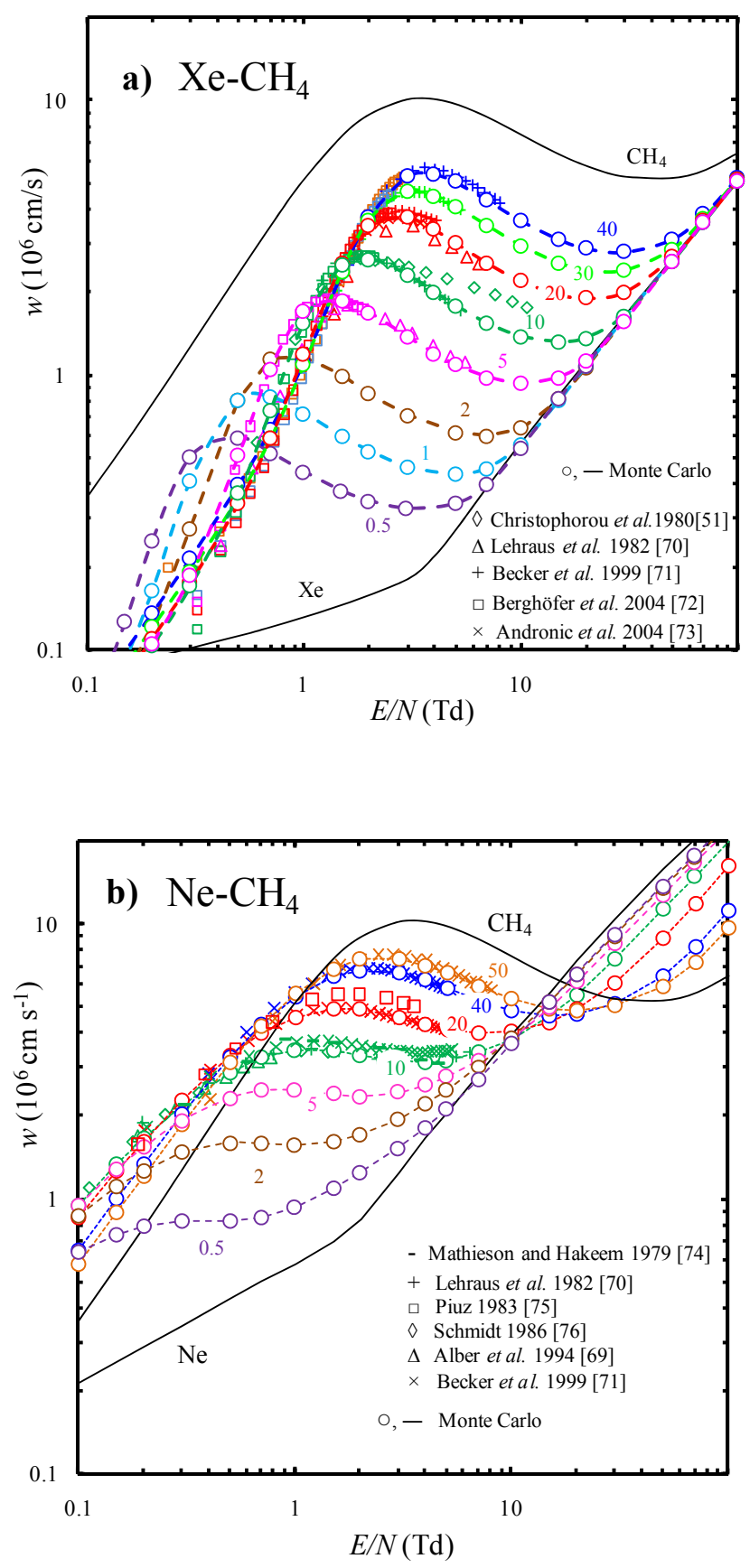

Figure 4. Monte Carlo and experimental drift velocities $w$ as a function of reduced electric field $E / N$ in a) $\mathrm{Xe}-\mathrm{CH}_{4}$ mixtures and b) $\mathrm{Ne}-\mathrm{CH}_{4}$ mixtures with the indicated $\mathrm{CH}_{4}$ concentrations (\%). The Monte Carlo $w$ curves for $\mathrm{Xe}, \mathrm{Ne}$ and $\mathrm{CH}_{4}$ are also included for reference. The dashed curves are included to guide the eye. 


\section{Results and discussion}

\subsection{Electron drift parameters in $\mathrm{Xe}, \mathrm{Ne}$, and $\mathrm{Xe}-\mathrm{CH}_{4}$ and $\mathrm{Ne}-\mathrm{CH}_{4}$ mixtures}

The electron scattering cross-sections used in the Monte Carlo simulation were tested by comparing the calculated drift parameters with experimental measurements. These parameters include electron mean energies $\varepsilon_{m}$, drift velocities $w$, reduced mobilities $\mu N=N w / E$, and characteristic energies $\varepsilon_{k l}=e D_{l} / \mu$ and $\varepsilon_{k t}=e D_{t} / \mu$, where $D_{l}$ and $D_{t}$ are the longitudinal and transversal diffusion coefficients. The calculations for Xe are shown together with the available experimental data in figure 2. Figure 3 shows similar results for $\mathrm{Ne}$, while figure 4 has the results for the drift velocities in mixtures of $\mathrm{Xe}$ and $\mathrm{Ne}$ with $\mathrm{CH}_{4}$. Good agreement is achieved in general. For example, in figures $2 \mathrm{a}$ and $3 \mathrm{a}$ the Monte Carlo $w$ values in Xe and in Ne agree within $2 \%$ on average with the data from $[36,53,56]$ and $[62,64,65]$, respectively. Similar good agreement was found in the case of $\mathrm{CH}_{4}$ discussed in a previous paper [14]. Although the cross-sections used in the present work may not guarantee the completeness established by the so called swarm method as usually required in gas discharge and plasma physics [77-81], figures 2 to 4 show that in the low $E / N$ range relevant for the present work (drift fields $E / N \sim<20$ Td near the photocathode), our calculations give sufficiently accurate drift parameters. In particular, they reproduce well known characteristic effects very sensitive to cross-sections, namely the anisotropy of diffusion when electrons drift under an electric field [36, 82-85], and negative differential conductivity [81, 86-90]. The NDC effect - a decrease of drift velocity with increasing $E / N$ - may be observed for instance in some mixtures of noble gases with molecular additives (e.g. $\mathrm{CH}_{4}$ ), due to the energy cooling of the electrons when large cross-sections for vibrational excitation emerge in the region of the Ramsaeur-Townsend minima of the elastic cross-sections (see figure1). This effect is also at the origin of the general increase in photoelectron extraction efficiency when $\mathrm{CH}_{4}$ is added to noble gases, as shown in [14] for Ar$\mathrm{CH}_{4}$ and in the present work for $\mathrm{Xe}-\mathrm{CH}_{4}$ and $\mathrm{Ne}-\mathrm{CH}_{4}$ mixtures. As pointed out above and as it can be inferred from [24, 25], electron cooling is a key factor to improve the transmission of electrons emitted from a cathode into gas media.

\subsection{Photoelectron extraction efficiency in $\mathrm{Xe}_{-} \mathrm{CH}_{4}$ and $\mathrm{Ne}-\mathrm{CH}_{4}$ mixtures}

3.2.1. Irradiation of CSI with monochromatic VUV photons. In this section we present the Monte Carlo results for the extraction efficiency $f$ in $\mathrm{Xe}_{-} \mathrm{CH}_{4}$ and $\mathrm{Ne}-\mathrm{CH}_{4}$ mixtures when the CsI photocathode is irradiated with monochromatic photons with energies $E_{\mathrm{ph}}$ in the $6.8 \mathrm{eV}$ to $9.8 \mathrm{eV}$ range. The applied electric field $E / N$ varies from $0.1 \mathrm{Td}$ to $40 \mathrm{Td}$.

The results are compared with our earlier data in $\mathrm{Xe}, \mathrm{Ar}, \mathrm{Ne}, \mathrm{CH}_{4}$, and $\mathrm{Ar}-\mathrm{CH}_{4}$ mixtures from $[13,14]$ in figures 5 and 6 , one surface for each gas as labelled. The data for the pure gases are represented in figure $5 \mathrm{a}$ as functions of $E / N$ and $E_{\mathrm{ph}}$, while the results in $\mathrm{Xe}_{-} \mathrm{CH}_{4}, \mathrm{Ar}-\mathrm{CH}_{4}$ and $\mathrm{Ne}-\mathrm{CH}_{4}$ mixtures are shown in figure $5 \mathrm{~b}$ where we have taken as an example $10 \% \mathrm{CH}_{4}$ content. Results for mixtures are also shown in figure 6 as a function of $E / N$ and $\mathrm{CH}_{4}$ concentration $\eta$, for incident photon energies 6.8 and $9.8 \mathrm{eV}$.

In figures 5 and 6 , we observe in general that $f$ increases as we go from $\mathrm{Xe}$ to $\mathrm{Ar}$ to $\mathrm{Ne}$ to $\mathrm{CH}_{4}$ or from $\mathrm{Xe}-\mathrm{CH}_{4}$ to $\mathrm{Ar}-\mathrm{CH}_{4}$ to $\mathrm{Ne}-\mathrm{CH}_{4}$. Note that $f$ is higher in each mixture than in the corresponding pure rare gas. We also observe that $f$ increases with $E / N$ and $\mathrm{CH}_{4}$ concentration, and $f$ decreases with $E_{\mathrm{ph}}$. However, exceptions may occur within specific regions, as observed in figures 5 and 6 (see also figures 7, 8 and 9), namely, $f$ may increase with $E_{\mathrm{ph}}$ (until it reaches a maximum, as for $\mathrm{Xe}_{-} \mathrm{CH}_{4}$ mixtures at low $E / N$ and $E_{\mathrm{ph}}$ in figure $5 \mathrm{~b}$ ), or $f$ may decrease with $\eta$ (after rising to a maximum, as in $\mathrm{Ar}-\mathrm{CH}_{4}$ at low $E / N$ and $E_{\mathrm{ph}}$ and in $\mathrm{Ne}-\mathrm{CH}_{4}$ at high $E / N$ and $E_{\mathrm{ph}}$, 
as shown respectively on figure $6 \mathrm{a}$ for $6.8 \mathrm{eV}$ and figure $6 \mathrm{~b}$ for $9.8 \mathrm{eV}$ ), or $f$ in $\mathrm{Ar}^{-} \mathrm{CH}_{4}$ may rise above $f$ in $\mathrm{Ne}-\mathrm{CH}_{4}$ (for low $E / N$ and $E_{\mathrm{ph}}$, see figure 6 a for $6.8 \mathrm{eV}$ ).

We note moreover that $f$ increases more rapidly with $E / N$ in $\mathrm{CH}_{4}$ and reaches considerably higher values than in the rare gases. In addition, $f$ increases very rapidly with the $\mathrm{CH}_{4}$ concentration $\eta$ in the mixtures when $\eta$ is small and is thus very sensitive to the value of $\eta$.

The behaviour of the photoelectron extraction efficiency $f$ in pure $\mathrm{Xe}, \mathrm{Ar}, \mathrm{Ne}, \mathrm{CH}_{4}$, and in Ar- $\mathrm{CH}_{4}$ mixtures has been extensively discussed before for $E_{\mathrm{ph}}$ and $E / N$ ranges similar to the present work $[13,14]$. In general, transmission is favoured by longer penetrations $\lambda$ (lower elastic scattering cross-sections) of the first free path of the photoelectrons into the gas (measured perpendicular to the photocathode), and by low photoelectron emission energy $\varepsilon_{0}$ or by a swift drop of photoelectron energy in inelastic collisions, the cooling effect we mentioned before. Similar considerations hold for the present results and may be outlined as follows.

As we go from $\mathrm{Xe}$ to Ar to $\mathrm{Ne}$ in the noble gases, $f$ increases in general because $\lambda$ and the energy losses in elastic collisions increase in that order. We note that the range of $\varepsilon_{0}$ is low, and if a photoelectron survives as far as the inelastic thresholds in $\mathrm{Xe}$, Ar or $\mathrm{Ne}(8.3 \mathrm{eV}, 11.6 \mathrm{eV}$ and $16.6 \mathrm{eV}$ respectively), just one inelastic collision may lower the electron energy to values $\varepsilon$ lower than $\varepsilon_{0}$ where recapture becomes energetically forbidden. However, inelastic collisions with the noble gas atoms are infrequent for the range of $E_{\mathrm{ph}}$ and $E / N$ investigated and do not contribute significantly to transmission $[13,14]$. On the contrary, in $\mathrm{CH}_{4}$ or in mixtures with $\mathrm{CH}_{4}$ the inelastic threshold becomes much lower $(0.16 \mathrm{eV})$, corresponding to vibrational excitation of the $\mathrm{CH}_{4}$ molecules. This process competes efficiently with elastic scattering (see figure 1) and plays a decisive role in increasing photoelectron transmission: energy losses by vibrational excitation may be of the order of $\varepsilon_{0}$, and a few vibrational collisions at an early stage can efficiently reduce electron energy and the chances of a return to the photocathode.

On the other hand, the parameter $f$ decreases in general with the incident photon energy $E_{\mathrm{ph}}$ in the range investigated. This happens because photoelectrons are emitted into the gas with increasing energies $\varepsilon_{0}$ as we move to higher $E_{\mathrm{ph}}$. For higher $\varepsilon_{0}$, chances of recapture become higher by a combination of effects: firstly, because photoelectron penetration lengths $\lambda$ become shorter as the scattering cross-sections $\sigma_{m}$ rise with $\varepsilon_{0}$ (particularly after the Ramsauer minima in $\mathrm{Ar}$ and $\mathrm{Xe}$ ), secondly, because larger energy losses are required to reduce the electron energy to a value that guarantees transmission.

We also note that the observed increase of $f$ with applied electric field $E / N$ is essentially related with increased electron guiding towards the anode as the strength of the electric field increases.

Departures of the extraction efficiency $f$ curves from these general trends are related to the fact that a combination of effects is involved and scattering cross-sections are complex functions of electron energy. In particular, in the mixtures the overlap of the cross-sections of the two components and the effective cross-section vary a great deal from one situation to another.

For a better understanding of these effects, some selected examples of the calculated $f$ curves at varying $E / N$ and $E_{\mathrm{ph}}$ are shown along figures 7,8 and 9, together with the corresponding inelastic ratios $\gamma_{v}$ and penetrations $\lambda$, where $\gamma_{v}=n_{v} / n_{t}$ is the ratio between the number $n_{v}$ of vibrational collisions with $\mathrm{CH}_{4}$ molecules and the total number $n_{t}$ of collisions in the gas, and $\lambda$ is the mean distance travelled by a photoelectron in the first free path in the gas, measured perpendicular to the photocathode surface. Among the different cases, one can determine the role played by vibrational excitation collisions and by the initial penetration length of the photoelectrons into the gas as discussed above, by checking the connection between the behaviour of the plotted $f$ curves and the curves for $\lambda$ and the vibrational ratio $\gamma_{v}$. 
3.2.2. Irradiation of CsI with a $\mathrm{Hg}(\mathrm{Ar})$ lamp. In this section, we present the Monte Carlo results obtained for the extraction efficiency $f$ when the photocathode is irradiated with a $\mathrm{Hg}(\mathrm{Ar}) \mathrm{lamp}$, allowing for a comparison with our experimental data from [11] and [12] where this lamp has been used. In the calculations, initial energies $\varepsilon_{0}$ of the photoelectrons are sampled from the energy distribution measured by [28] when a CsI photocathode was irradiated with photons from the VUV peak of this lamp.

The Monte Carlo results obtained in $\mathrm{Xe}, \mathrm{Ne}, \mathrm{CH}_{4}, \mathrm{Xe}-\mathrm{CH}_{4}$ and $\mathrm{Ne}-\mathrm{CH}_{4}$ are shown in figure 10 together with the experimental measurements where we see that the measurements are consistent with the Monte Carlo predictions. The deviations from the calculated data observed at progressively lower fields at lower $\eta$ values and in pure Xe or $\mathrm{Ne}$ are due to the effect of positive feedback from Xe or Ne self-scintillation [13], not included in the present calculated curves.

The remaining discrepancies between the Monte Carlo results and the measurements are attributed to several factors. Firstly, $f$ is very sensitive to the photoelectron energy $\varepsilon_{0}$ and to the $\varepsilon_{0}$ distribution profile, as was shown in [14] and in [24-26], but due to different surface conditions [23] and temperature (thermionic emission [26]) on the photocathode, the photoelectron emission spectra in the measurements is not expected to exactly match the $\varepsilon_{0^{-}}$ distribution used in the simulations (the distribution measured in [28] for the lamp). Secondly, electron reflection at the photocathode surface [23-26] (not included in the simulations) will also play a role: for instance, if a reflection coefficient of $15 \%$ is assumed, the Monte Carlo $f$ curves in $\mathrm{Ne}^{-\mathrm{CH}_{4}}$ (figure 10b) become close to the experimental data. Uncertainty in the mixture composition is an additional factor: at low $E / N, f$ is very sensitive to even very small concentrations of $\mathrm{CH}_{4}$, and is expected to be equally sensitive to impurity traces contaminating the mixtures. This can explain why the discrepancies between Monte Carlo and measurements in $\mathrm{Xe}-\mathrm{CH}_{4}$ (figure 10a) appear larger than in $\mathrm{Ne}-\mathrm{CH}_{4}$ (figure $10 \mathrm{~b}$ ). Finally we note that the $\varepsilon_{0}$ distribution used in the calculations of $f$ was measured for $185 \pm 0.5 \mathrm{~nm}$ photons from the lamp VUV peak [28] while in our $f$ measurements the photons from the entire peak, albeit narrow (fwhm 5nm), will reach the photocathode.

\section{Conclusions}

Backscattering of the photoelectrons emitted from a photocathode into gas medium may significantly reduce the photoelectron transmission, especially in noble gases, but the addition of a molecular gas like $\mathrm{CH}_{4}$ significantly reduces the effect. In the present work, a Monte Carlo study of the extraction efficiency $f$ for photoelectrons emitted from a CsI photocathode into $\mathrm{Xe}-\mathrm{CH}_{4}$ and $\mathrm{Ne}-\mathrm{CH}_{4}$ mixtures is presented. The behaviour of the results is discussed in terms of the electron scattering in the gas, analyzing the dependence of $f$ on the mixture composition, density-reduced electric field $E / N$ [0.1-40 Td range], and incident photon energy $E_{\mathrm{ph}}$ [6.7-9.8 eV (185-127 nm) range]. The calculated results are compared with earlier data in $\mathrm{Ar}-\mathrm{CH}_{4}$ mixtures and in the pure gases $\mathrm{Xe}, \mathrm{Ar}, \mathrm{Ne}$ and $\mathrm{CH}_{4}$. A good agreement is found with the available experimental measurements for $f$ when the CsI photocathode is irradiated with a $\operatorname{Hg}(\mathrm{Ar})$ lamp. 

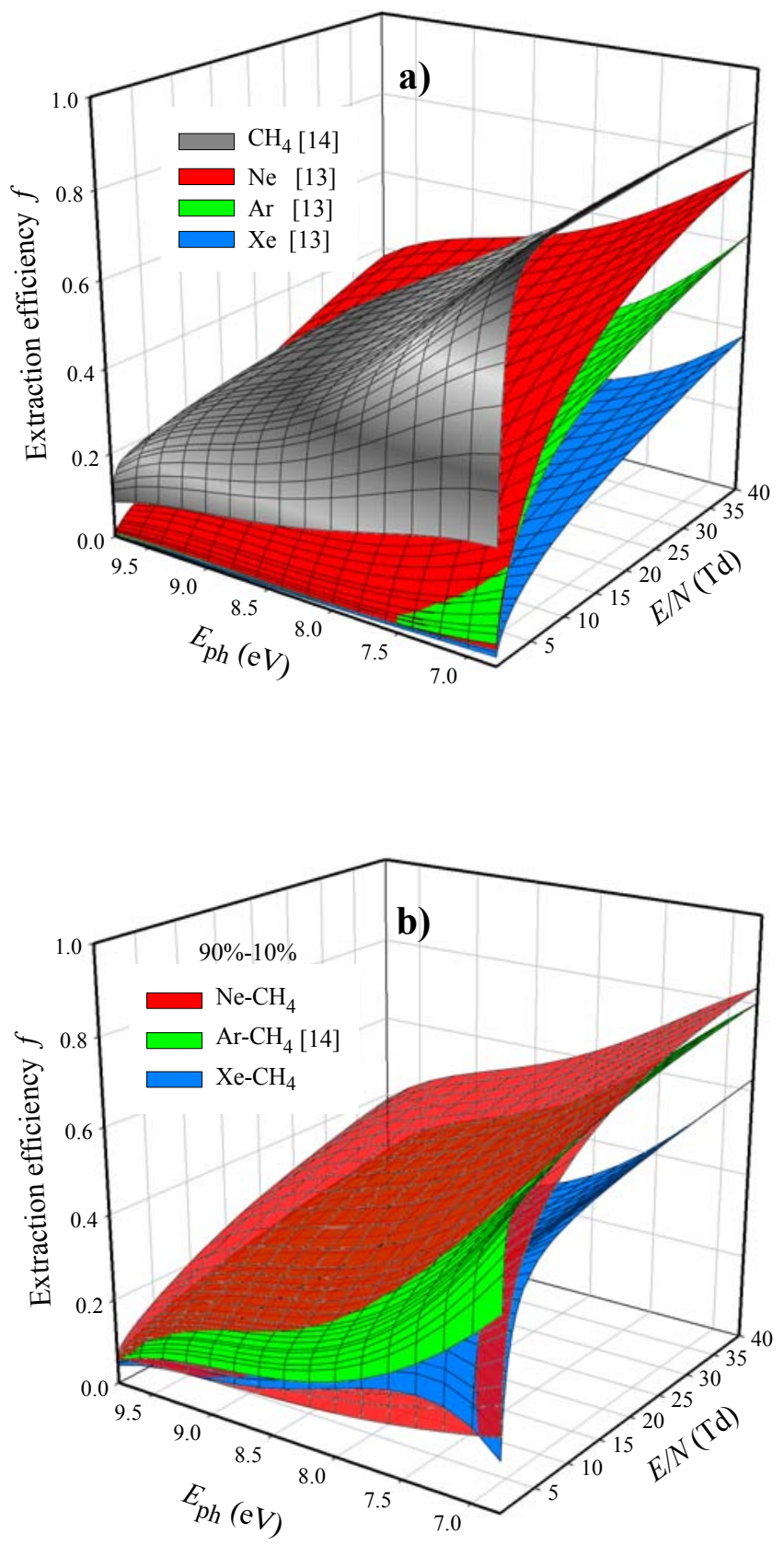

Figure 5. Monte Carlo results for the extraction efficiency $f$ as a function of reduced electric field $E / N$ and incident photon energy $E_{\mathrm{ph}}$ for photoelectrons emitted from a CsI photocathode into a) pure gases $\mathrm{Xe}, \mathrm{Ar}, \mathrm{Ne}$ and $\mathrm{CH}_{4}$, and b) the $90 \%-10 \% \mathrm{Xe}_{-} \mathrm{CH}_{4}, \mathrm{Ar}-\mathrm{CH}_{4}$ and $\mathrm{Ne}-\mathrm{CH}_{4}$ mixtures. 

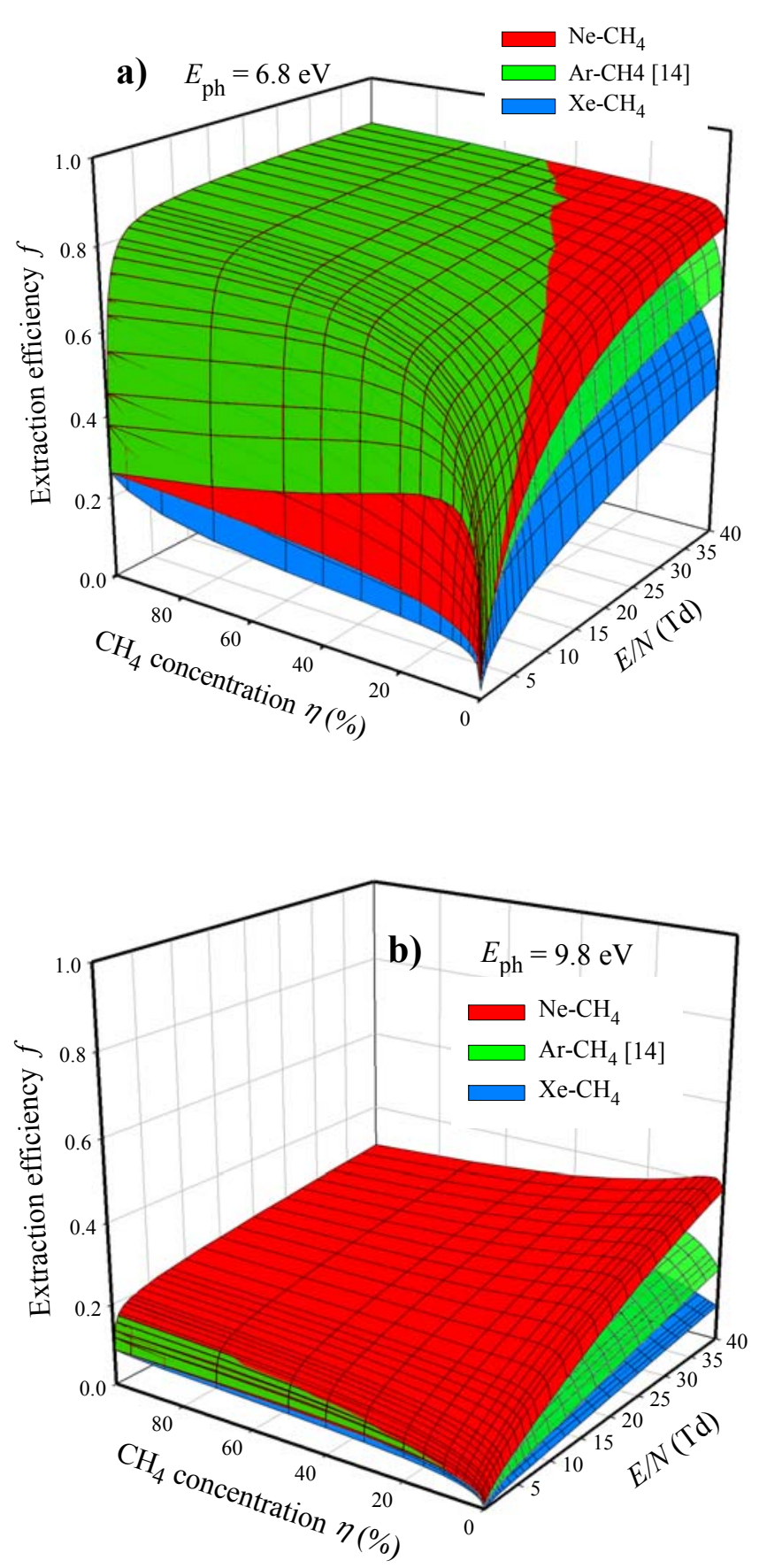

Figure 6. Monte Carlo results for the extraction efficiency $f$ of photoelectrons emitted from a CsI photocathode into $\mathrm{Xe}-\mathrm{CH}_{4}, \mathrm{Ar}-\mathrm{CH}_{4}$ and $\mathrm{Ne}-\mathrm{CH}_{4}$ mixtures as a function of reduced electric field $E / N$ and $\mathrm{CH}_{4}$ concentration $\eta$ for incident photon energies a) $E_{\mathrm{ph}}=6.8 \mathrm{eV}$ and b) $E_{\mathrm{ph}}=9.8 \mathrm{eV}$. 

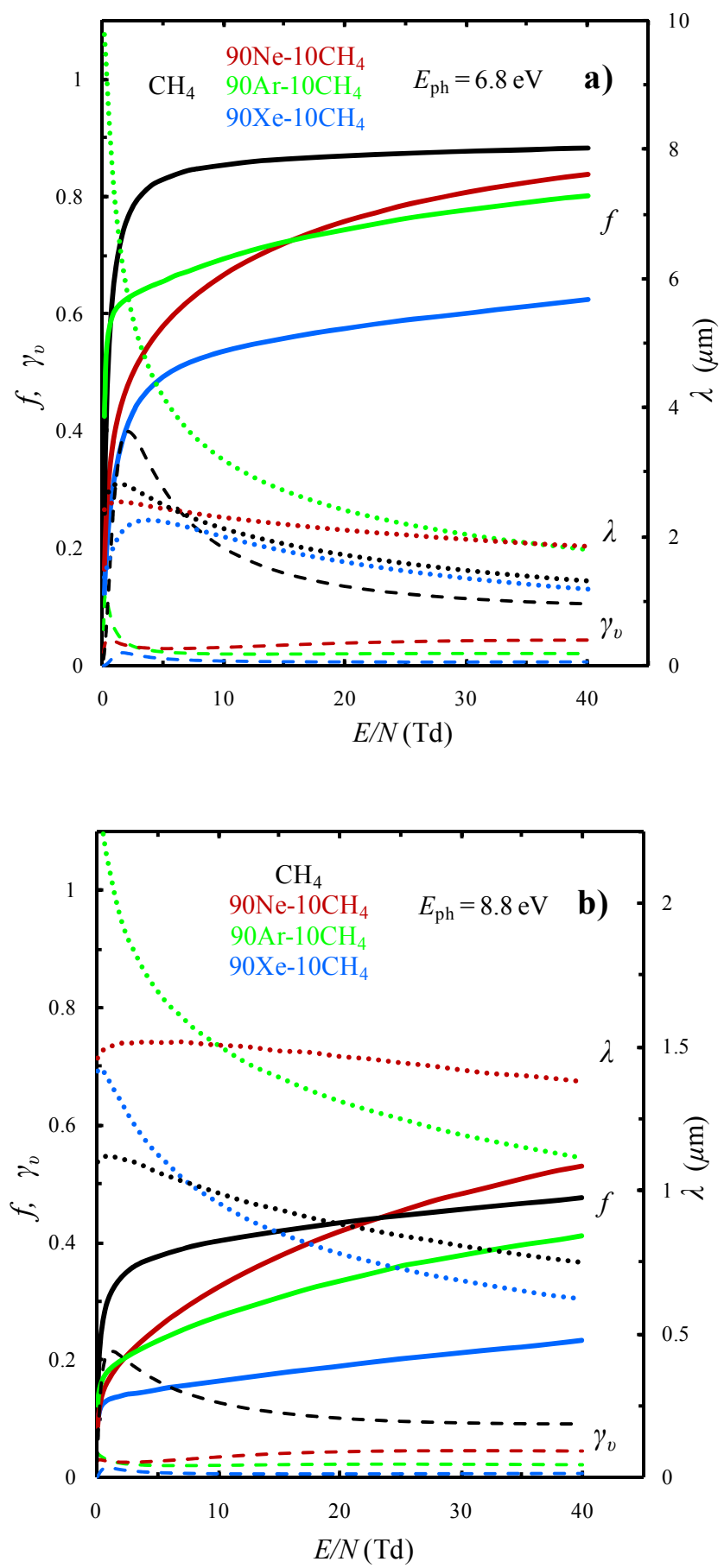

Figure 7. Monte Carlo extraction efficiency $f(-)$ for photoelectrons emitted from $\mathrm{CsI}$ into $\mathrm{CH}_{4}$ and into the $90 \%-10 \% \mathrm{Ne}-\mathrm{CH}_{4}, \mathrm{Ar}-\mathrm{CH}_{4}, \mathrm{Xe}-\mathrm{CH}_{4}$ mixtures together with the corresponding photoelectron penetration $\lambda(\bullet \bullet)$ and vibrational excitation ratio $\gamma_{v}=n_{v} / n_{t}(---)$, as a function of the applied electric field $E / N$ for incident photon energies a) $E_{\mathrm{ph}}=6.8 \mathrm{eV}$ and b) $E_{\mathrm{ph}}=8.8 \mathrm{eV}$. 

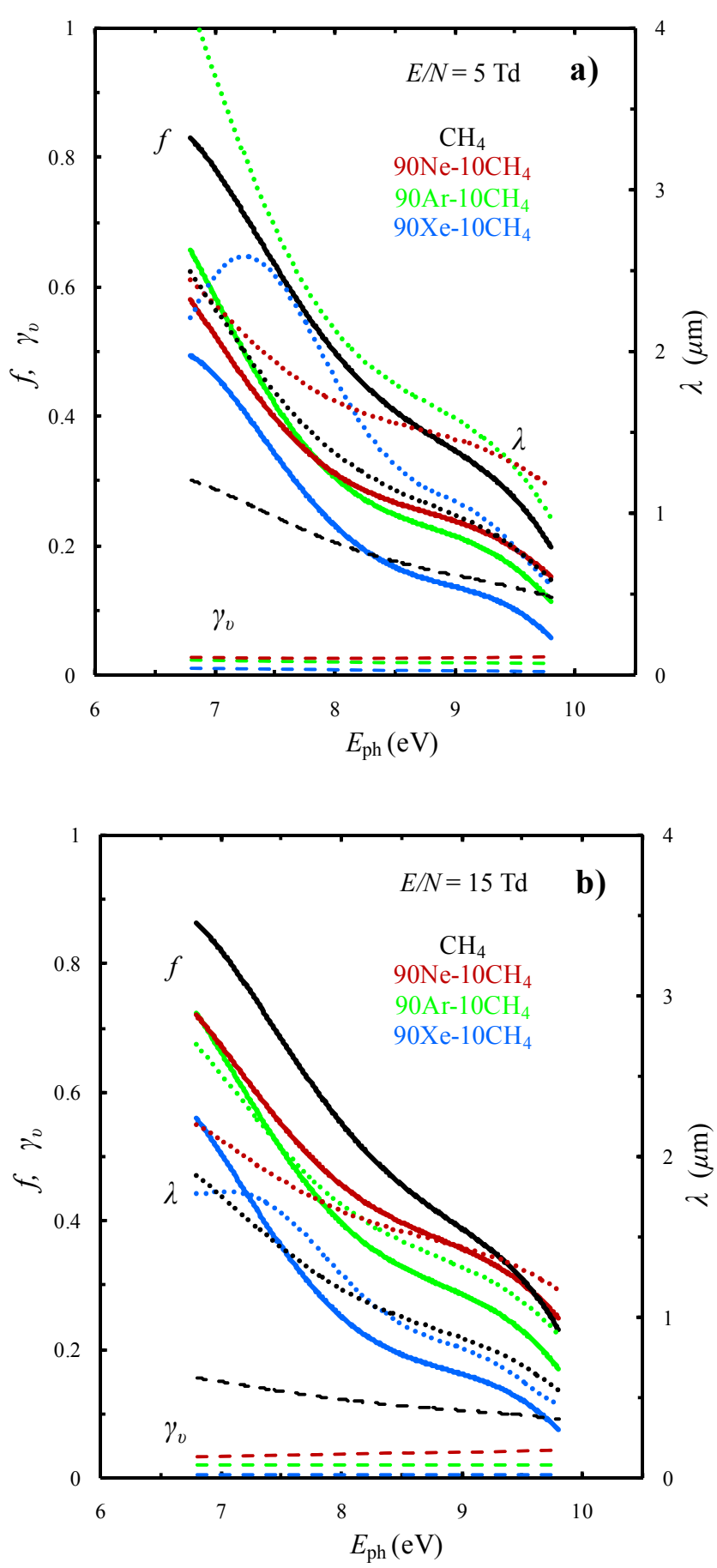

Figure 8. Monte Carlo extraction efficiency $f(-)$ for photoelectrons emitted from $\mathrm{CsI}$ into $\mathrm{CH}_{4}$ and into the $90 \%-10 \% \mathrm{Ne}-\mathrm{CH}_{4}, \mathrm{Ar}-\mathrm{CH}_{4}, \mathrm{Xe}-\mathrm{CH}_{4}$ mixtures together with the corresponding photoelectron penetration $\lambda(\bullet \bullet)$ and vibrational excitation ratio $\gamma_{v}=n_{v} / n_{t}(---)$, as a function of incident photon energies $E_{\mathrm{ph}}$ for the applied electric fields a) $E / N=5 \mathrm{Td}$ and b) $E / N=15 \mathrm{Td}$. 

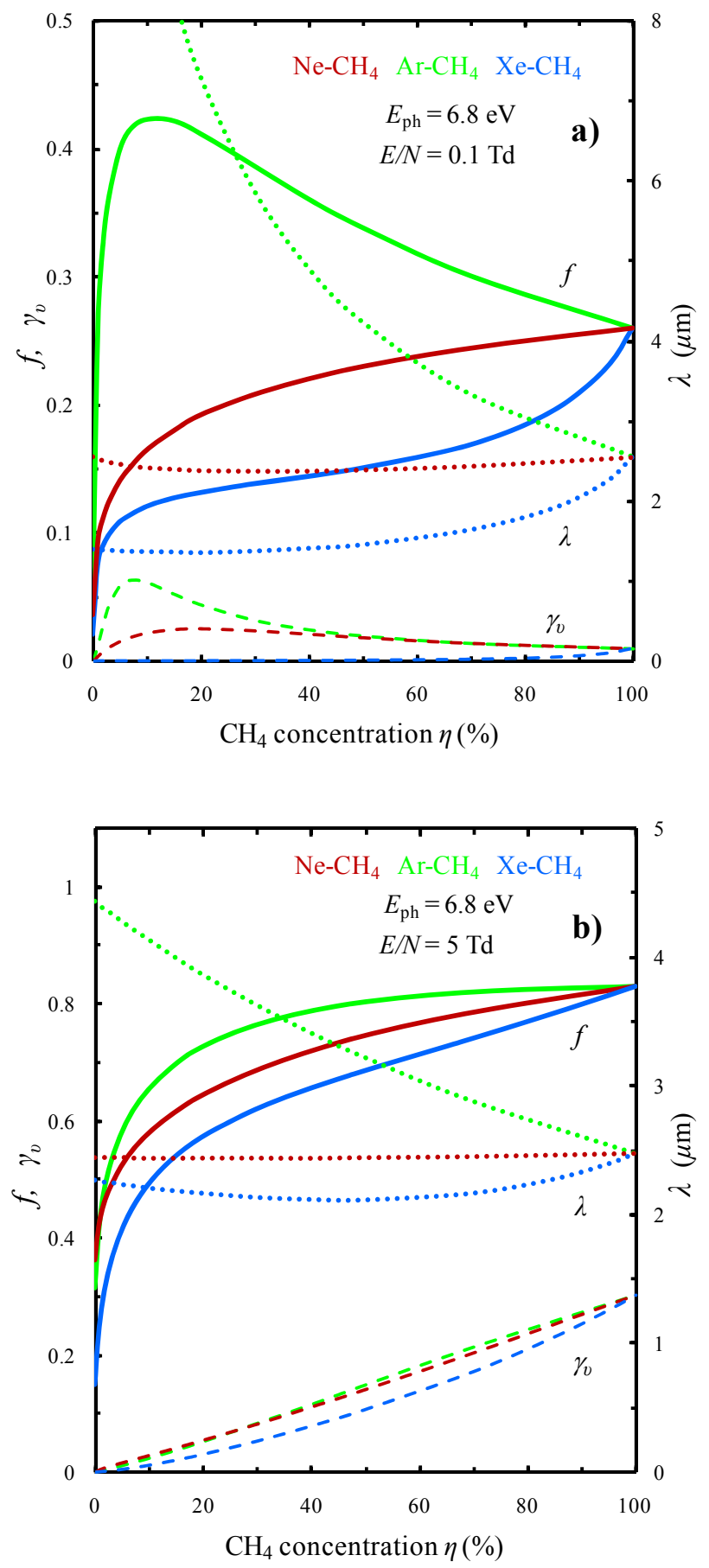

Figure 9. Monte Carlo extraction efficiency $f(-)$ for photoelectrons emitted from CsI into Ne$\mathrm{CH}_{4}, \mathrm{Ar}-\mathrm{CH}_{4}$ and $\mathrm{Xe}-\mathrm{CH}_{4}$ mixtures together with the corresponding photoelectron penetration $\lambda$ $(\cdots)$ and vibrational excitation ratio $\gamma_{v}=n_{v} / n_{t}(---)$, as a function of $\mathrm{CH}_{4}$ concentration $\eta$ for incident photon energy $E_{\mathrm{ph}}=6.8 \mathrm{eV}$ and applied electric fields a) $E / N=0.1 \mathrm{Td}$ and b) $E / N=5 \mathrm{Td}$. 

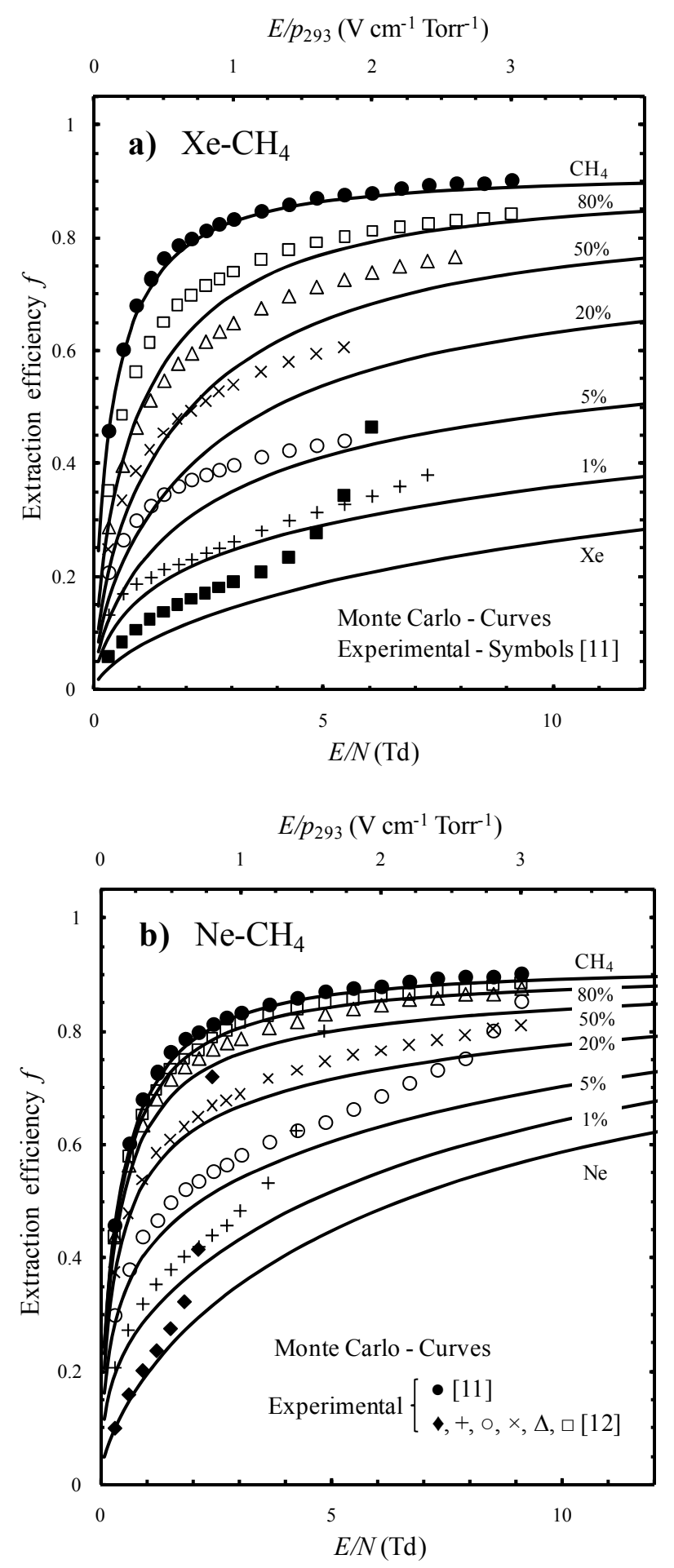

Figure 10. Monte Carlo and measured extraction efficiency $f$ as a function of $E / N$ for the photoelectrons emitted from CsI into a) $\mathrm{Xe}_{-} \mathrm{CH}_{4}$ and b) $\mathrm{Ne}-\mathrm{CH}_{4}$ mixtures with the indicated $\mathrm{CH}_{4}$ concentrations $\eta(\%)$ when the CsI photocathode is irradiated with a $\mathrm{Hg}(\mathrm{Ar})$ lamp. The effect of positive feedback from Xe or Ne self scintillation (not included in the Monte Carlo calculations) is visible on the experimental results in $\mathrm{Xe}, \mathrm{Ne}$ and in the mixtures with lower $\eta$. 


\section{Acknowledgments}

This work was carried out at Centro de Instrumentação (Research Unit 217/94), Physics Department, University of Coimbra, Portugal, and was supported by FEDER and POCI2010 programs through FCT (Fundação para a Ciência e Tecnologia, Portugal) projects POCI/FP/63418/2005 and POCI/FP/81935/2007. J. Escada acknowledges support from FCT Grant SFRH/BD/22177/2005.

\section{References}

[1] Giomataris Y, Charpak G, Peskov V and Sauli F. 1992 New generation of Cherenkov counters Nucl. Instr. Meth. A 323431

[2] M. Chen et al. 1994 Results of a first beam test of Hadron Blind Trackers Nucl. Instr. Meth. A 346 120

[3] Breskin A 1996 CsI VUV photocathodes history and mystery Nucl. Instr. Meth. A 371116

[4] Francke T, Peskov V, Rodionov I and Sokolova T 2002 Novel Position-Sensitive Gaseous Detectors with Solid Photocathodes IEEE Trans. Nucl. Sci. 49977

[5] Maia J M, Mörmann D, Breskin A, Chechik R, Veloso J F C A and dos Santos J M F 2007 SingleUV-photon 2-D imaging with multi-GEM detectors Nucl. Instr. Meth. A $\mathbf{5 8 0} 373$

[6] Chechik R and Breskin A 2008 Advances in gaseous photomultipliers Nucl. Instr. Meth. A 595116

[7] Di Mauro A, Nappi E, Posa F, Breskin A, Buzulutskov A, Chechik R, Biagi S F, Paic G, Piuz F 1996 Photoelectron backscattering effects in photoemission from CsI into gas media Nucl. Instr. Meth. A 371137

[8] Buzulutskov A, Breskin A, Chechik R, Garty G, Sauli F and Shekhtman L 2000 The GEM photomultiplier operated with noble gas mixtures Nucl. Instr. Meth. A 443164

[9] Breskin A, Buzulutskov A and Chechik R 2002 GEM photomultiplier operation in $\mathrm{CF}_{4}$ Nucl. Instr. Meth. A 483670

[10]Coelho L C C, Ferreira H M N B L, Lopes J A M, Dias T H V T, Ferreira L F R, dos Santos J M F, Breskin A and Chechik R 2007 Measurement of the photoelectron-collection efficiency in noble gases and methane Nucl. Instr. Meth. A 581190

[11]Coelho L C C, Lopes J A M, Escada J, Dias T H V T, dos Santos J M F 2009 Photoelectron transmission efficiency in $\mathrm{Ar}-\mathrm{CH}_{4}$ and $\mathrm{Xe}-\mathrm{CH}_{4}$ mixtures: Experimental results Nucl. Instr. Meth. A $\mathbf{6 0 7} 587$

[12]Escada J, Coelho L C C, Dias T H V T, Lopes J A M, dos Santos J M F and Breskin A 2009 Measurements of photoelectron extraction efficiency from CsI into mixtures of $\mathrm{Ne}$ with $\mathrm{CH}_{4}, \mathrm{CF}_{4}$, $\mathrm{CO}_{2}$ and $\mathrm{N}_{2}$ Proceedings of MPGD2009-1 ${ }^{\text {st }}$ Micro Pattern Gas Detectors Conference (12-15 June 2009, Kolympari, Crete, Greece) JINST - J. of Instrumentation, accepted for publication

[13]Dias T H V T, Rachinhas P J B M, Lopes J A M, Santos F P, Távora L M N, Conde C A N and Stauffer A D 2004 The transmission of photoelectrons emitted from CsI phocathodes into Xe, Ar, $\mathrm{Ne}$ and their mixtures: a Monte Carlo study of the dependence on $\mathrm{E} / \mathrm{N}$ and incident VUV photon energy J. Phys. D: Appl. Phys. 37540

[14]Escada J, Dias T H V T, Rachinhas P J B M, Lopes J A M, Santos F P, Távora L M N, Conde C A N and Stauffer A D 2007 A Monte Carlo study of backscattering effects in the photoelectron emission from CsI into $\mathrm{CH}_{4}$ and $\mathrm{Ar}-\mathrm{CH}_{4}$ mixtures JINST - J. of Instrumentation $2 \mathrm{P} 08001$

[15]Dias T H V T, Santos F P, Conde C A N and Stauffer A D 1993 Monte Carlo simulation of x-ray absorption and drift in gaseous xenon Phys. Rev. A 482887

[16] Huxley L G H and Crompton R W 1973 The Diffusion and Drift of Electrons in Gases, WileyInterscience, New York

[17]Theobald J K 1953 Investigation of back-diffusion of photoelectrons in various standard gases as it affects secondary electron emission coefficients J. Appl. Phys $\mathbf{2 4} 123$

[18]Dahlquist J A 1962 Back diffusion of electrons in nitrogen, hydrogen and argon Phys. Rev. 1281988

[19]Burch D S and Whealton J H 1977 Monte Carlo calculation of electron back diffusion in a Townsend discharge J. Appl. Phys $\mathbf{4 8} 2213$ 
[20]Vidaud P H and von Engel A 1978 Back-diffusion of electrons in argon in the presence of an electric field J. Phys. D: Appl. Phys. 111397

[21]Pareathumby S and Segur P 1979 Determination of the transmission factor of electrons in helium and argon for high values of the ratio electric field upon pressure Lettere al Nuovo Cimento $\mathbf{2 6} 243$

[22]Nagorny V P and Drallos P J 1997 Effective secondary emission coefficient in a high-pressure noble gas Plasma Sources Sci. Technol. 6212

[23]Phelps A V and Petrović Z Lj 1999 Cold cathode discharges and breakdown in argon: surface and gas production of secondary electrons Plasma Sources Sci. Technol. 8 R21

[24]Radmilović M and Petrović Z Lj 2000 Modeling of back-diffusion of electrons in argon Eur. Phys. J. Appl. Phys. 1135

[25]Radmilović-Radjenović M, Nina A and Nikitović Ž 2009 Monte Carlo simulation of back-diffusion of electrons in nitrogen Nucl. Instr. Meth. B 267302

[26]Benilov M S, Naidis G V, Petrović Z Lj, Radmilović-Radjenović M and Stojković A 2006 Escape factors for thermionic cathodes in atomic gases in a wide electric field range $2006 \mathrm{~J}$. Phys. D: Appl. Phys. 392959

[27]Di Stefano T H and Spicer W E 1973 Photoemission from CsI: experiment Phys. Rev. B 71554

[28]Shefer E, Breskin A, Boutboul T, Chechik R, Singh B K, Cohen H and Feldman I 2002 Photoelectron transport in CsI and $\mathrm{CsBr}$ coating films of alkali antimonide and CsI photocathodes J. Appl. Phys. 924758

[29]Shimizu R and Ze Jun D 1992 Monte Carlo modelling of electron-solid interactions Rep. Prog. Phys. 55487

[30]Skullerud H R 1968 The stochastic computer simulation of ion motion in a gas subjected to a constant electric field J. Phys. D: Appl. Phys. 11567

[31]Lin S L and Bardsley J N 1978 The null-event method in computer simulation Comput. Phys. Commun. 15161

[32]Brennan M J 1991 Optimization of Monte Carlo codes using null collision techniques for experimental simulation at low E/N IEEE Trans. Plasma Sci. 19256

[33]S. Longo 2006 Monte Carlo simulation of charged species kinetics in weakly ionized gases Plasma Sources Sci. Technol. $15 \mathrm{~S} 181$

[34]McEachran R P and Stauffer A D 1987 Relativistic low-energy elastic and momentum transfer cross sections for electron scattering from xenon J. Phys. B: At. Mol. Opt. Phys. 203483

[35]Koizumi T, Shirakawa E and Ogawa I 1986 Momentum transfer cross sections for low-energy electrons in krypton and xenon from characteristic energies J. Phys. B: At. Mol. Phys. 19. 2331

[36]Pack J L, Voshall R E, Phelps A V and Kline L E 1992 Longitudinal electron diffusion coefficients in gases: Noble gases J. Appl. Phys. 715363

[37]Hayashi M 1981: Recommended values of transport cross sections for elastic collisions and total collision cross sections for electrons in atomic and molecular gases Report. IPPJ-AM-19 Institute of Plasma Physics, Nagoya University

[38]Hayashi M 1983 Determination of electron-xenon total excitation cross-sections, from threshold to $100 \mathrm{eV}$, from experimental values of Townsend's $\alpha$ J. Phys. D: Appl. Phys. 16581

[39]Puech V and Mizzi S 1991 Collision cross sections and transport parameters in neon and xenon $J$. Phys. D: Appl. Phys. 241974

[40]Rapp D and Englander-Golden P 1965 Total cross sections for ionization and attachment in gases by electron impact. I. Positive ionization J. Chem. Phys. 431464

[41]McEachran R P and Stauffer A D 1985 Electron scattering from Ne Phys. Lett. A 107397

[42]Brusa R S, Karwasz G P and Zecca A 1996 Analytical partitioning of total cross sections for electron scattering on noble gases Z. Phys. D 38279

[43]Zecca A, Karwasz G P and Brusa R S 2000 Electron scattering by Ne, Ar and $\mathrm{Kr}$ at intermediate and high energies, 0.5-10 keV J. Phys. B: At. Mol. Opt. Phys. 33843

[44]Krishnakumar E and Srivastava S K 1988 Ionisation cross sections of rare-gas atoms by electron impact J. Phys. B: At. Mol. Opt. Phys. 211055

[45]Shirai T, Tabata T, Tawara $\mathrm{H}$ and Itikawa $\mathrm{Y} 2002$ Analytic cross sections for electron collisionswith hydrocarbons: $\mathrm{CH}_{4}, \mathrm{C}_{2} \mathrm{H}_{6}, \mathrm{C}_{2} \mathrm{H}_{4}, \mathrm{C}_{2} \mathrm{H}_{2}, \mathrm{C}_{3} \mathrm{H}_{8}$, and $\mathrm{C}_{3} \mathrm{H}_{6}$ Atomic Data and Nuclear Data Tables 80 147 
[46]English W N and Hanna G C 1953 Grid ionization chamber measurements of electron drift velocities in gas mixtures Can. J. Phys. 31768

[47]Bowe J C 1960 Drift velocity of electrons in nitrogen, helium, neon, argon, krypton, and xenon Phys. Rev. 1171411

[48]Pack J L, Voshall R E and Phelps A V 1962 Drift velocities of slow electrons in krypton, xenon, deuterium, carbon monoxide, carbon dioxide, water vapor, nitrous oxide, and ammonia Phys. Rev. 1272084

[49]Huang S S-S and Freeman G R 1978 Electron mobilities in gaseous, critical, and liquid xenon: Density, electric field, and temperature effects: Quasilocalization J. Chem. Phys. 681355

[50]Cumpstey D E and Vass D G 1980 The scintillation process in gas proportional scintillation detectors with uniform electric fields Nucl. Instr. Meth. 171473

[51]Christophorou L G, Maxey D V, McCorkle D L and Carter J G 1980 Xe-containing fast gas mixtures for gas-filled detectors Nucl. Instr. Meth. 171491

[52]Dmitrenko V V, Romanuk A S, Suchkov S I and Uteshev Z M 1983 Mobility of Electrons in a HighDensity Gaseous Xenon, J. of Tech. Phys. (USSR) 53 2343, translation in Sov. Phys - Tech. Phys. (USA) 28 1440, as quoted in [34]

[53]Hunter S R, Carter J G and Christophorou L G 1988 Low-energy electron drift and scattering in krypton and xenon Phys. Rev. A 385539

[54]Hashimoto T and Nakamura Y 1990 Papers of Gas Discharge Technical Committee ED-90-61 Japan: IEE, as quoted in Suzuki M, Taniguchi T, Yoshimura N and Tagashira H 1992 Momentum transfer cross section of xenon deduced from electron drift velocity data J. Phys. D: Appl. Phys. 2550

[55]Patrick E L, Andrews M L and Garscadden A 1991 Electron drift velocities in xenon and xenonnitrogen gas mixtures Appl. Phys. Lett. 593239

[56]Šašić O, Jovanović J, Petrović Z Lj, de Urquijo J, Castrejón-Pita J R, Hernández-Ávila J L and Basurto E 2005 Electron drift velocities in mixtures of helium and xenon and experimental verification of corrections to Blanc's law Phys. Rev. E 71046408.

[57]Kobayashi S, Hasebe N, Igarashi T, Miyachi T, Miyajima M, Okada H, Doke T, Shibamura E, Dmitrenko V V and Vlasik K F 2004 Ratio of transverse diffusion coefficient to mobility of electrons in high-pressure xenon Jap. J. Appl. Phys. 435568

[58]Kobayashi S et al 2005 Measurements of electron transport coefficients in high-pressure xenon gas Proc. of XeSAT2005 - $2^{\text {nd }}$ Int. IWorkshop on Applications of Rare Gas Xenon to Science and Technology (8-10 March 2005, Waseda University, Tokyo, Japan) 9-12

[59]Nielsen R A 1936 Absolute values of the electron drift velocity in nitrogen, helium, neon and argon Phys. Rev. $\mathbf{5 0} 950$

[60]Gill E W and von Engel A 1949 Starting Potentials of electrodeless discharges Proc. Royal Soc. (London) A 197107

[61]Pack J L and Phelps A V 1961 Drift velocities of slow electrons in helium, neon, argon, hydrogen, and nitrogen Phys. Rev. 121798

[62]Takayama K 1962 Probe measurements in quiescent plasmas Rev. Elec. Commun. Lab. Tokyo 10100 as quoted in Dutton J 1975 A survey of electron swarm data J. Phys. Chem. Ref. Data 4577

[63]Anderson J M 1964 Hall effect and electron drift velocities in the plasma of the positive column Phys. Fluids 71517

[64]Robertson A G 1972 The momentum transfer cross section for low energy electrons in neon J. Phys. B: At. Mol. Phys. 5648

[65]Kücükarpaci H N, Saelee H T and J. Lucas 1981 Electron swarm parameters in helium and neon $J$. Phys. D: Appl. Phys. 149

[66]Fletcher T 1956 in Electron and Ion Swarms L. G. Christophorou ed., Pergamon, New York, as quoted in Peisert A and Sauli F 1984 Drift and diffusion of electrons in gases: a compilation CERN Report 84-08

[67]Skelding R 1984 Ph.D. Thesis, University of Leicester, U.K, as quoted in Fraser G W and Mathieson E 1986 Monte Carlo calculation of electron transport coefficients in counting gas mixtures II. Mixtures containing neon and carbon dioxide Nucl. Instr. Meth. A 247566

[68]Koizumi T, Murakoshi H, Yamamoto S and Ogawa I 1984 The characteristic energy and momentum transfer cross section for low-energy electrons in neon J. Phys. B: At. Mol. Phys. 174387 
[69]Alber T, Eckardt V, Fessler H, Schönfelder S and Seyboth P 1994 A study of argon, neon and helium based gas mixtures for improving the spatial resolution in time projection chambers Nucl. Instr. Meth. A 34956

[70]Lehraus I, Matthewson R and Tejessy W 1982 dE/dx measurements in Ne, Ar, Kr, Xe and pure hydrocarbons Nucl. Instr. Meth. 200199

[71]Becker U, Dinner R, Fortunato E, Kirchner J, Rosera K and Uchida Y 1999 Consistent measurements comparing the drift features of noble gas mixtures Nucl. Instr. Meth. A $\mathbf{4 2 1}$ 54, numerical data at http://cyclotron.mit.edu/drift/drift.html

[72]Berghöfer Th, Blümer J and Hörandel J R 2004 A measurement of drift velocities of electrons in xenon-methane mixtures Nucl. Instr. Meth. A 525544

[73]Andronic A, Biagi S, Braun-Munzinger P, Garabatos C and Tsiledakis G 2004 Drift velocity and gain in argon- and xenon-based mixtures Nucl. Instr. Meth. A 523302

[74]Mathieson E and El Hakeem N 1979 Calculation of electron transport coefficients in counting gas mixtures Nucl. Instr. Meth. 159489

[75]Piuz F 1983 Measurement of the longitudinal diffusion of a single electron in gas mixtures used in proportional counters Nucl. Instr. Meth. 205425

[76]Schmidt B 1986 Drift properties of electrons in methane and methane noble gas mixtures Nucl. Instr. Meth. A 252579

[77]Ohmori Y, Kitamori K, Shimozuma M and Tagashira H 1986 Boltzmann equation analysis of electron swarm behaviour in methane J. Phys. D: Appl. Phys. 1943.

[78]Crompton R W 1994 Benchmark measurements of cross sections for electron collisions: electron swarm methods Adv. At. Mol. Opt. Phys. 3397

[79]Sakai Y 2002. Database in low temperature plasma modeling Appl. Surf. Sci. 192327

[80]Šašić O, Malović G, Strinić A, Nikitović Ž and Petrović Z Lj 2004 Excitation coefficients and crosssections for electron swarms in methane New Journal of Physics 674

[81]Petrović Z Lj, Šuvakov M, Nikitović Z, Dujko S, Šašić O, Jovanović J, Malović G and Stojanović V 2007 Kinetic phenomena in charged particle transport in gases, swarm parameters and cross section data Plasma Sources Sci. Technol. 16 S1

[82]Skullerud H R Longitudinal diffusion of electrons in electrostatic fields in gases $1969 \mathrm{~J}$ Phys. B: At. Mol. Opt. Phys 2696

[83]Parker J H and Lowke J J 1969 Theory of electron diffusion parallel to electric fields. I. Theory Phys. Rev. 181 290; Lowke J J and Parker J H 1969 Theory of electron diffusion parallel to electric fields. II. Application to real gases Phys. Rev. 181302.

[84]Robertson A G and Rees J A 1972 A note on the longitudinal diffusion of electrons in argon Aust. J. Phys. 25637

[85]Elford T 1974 The ratio $D_{\mathrm{L}} / \mu$ for electrons in helium at $293 \mathrm{~K}$ Aust. J. Phys. 27235

[86]Long Jr. W H, Bailey W F and Garscadden A 1976 Electron drift velocities in molecular-gas-rare-gas mixtures Phys. Rev. A 13471

[87]Petrović Z Lj, Crompton R W and Haddad G N 1984 Model calculations of negative differential conductivity in gases Aust. J. Phys. 3723

[88]Vrhovac S B and Petrović Z Lj 1996 Momentum transfer theory of nonconservative charged particle transport in mixtures of gases: general equations and negative differential conductivity Phys. Rev. E 534012

[89]Jelenak A, Jovanović J V, Bzenić S A, Vrhovac S B, Manola S S, Tomčik B and Petrović Z Lj 1995 The influence of excited states on the kinetics of excitation and dissociation in gas mixtures containing methane Diamond and Related Materials 41103

[90]Li B, White R D and Robson R E 2002 Spatially periodic structures in electron swarms: ionization, NDC effects and multi-term analysis J. Phys. D: Appl. Phys. 352914 